Tropical Journal of Pharmaceutical Research September 2021; 20 (9): 1975-1981

ISSN: $1596-5996$ (print); 1596-9827 (electronic) (C) Pharmacotherapy Group, Faculty of Pharmacy, University of Benin, Benin City, 300001 Nigeria

\title{
Clinical efficacy of a combination of propofol and etomidate in pediatric anesthesia, and its effect on vital indices in patients
}

\author{
Li Li, Yangzi Ding, Junli Yao, Qiongge Sun, Fengchao Zhang* \\ Department of Anesthesiology, Xuzhou Children's Hospital, Xuzhou Medical University, Xuzhou 221002, PR China
}

*For correspondence: Email: zhangfengchao96@126.com; Tel: +86-15895229712

Sent for review: 1 May 2021

Revised accepted: 1 September 2021

\begin{abstract}
Purpose: To study the clinical effectiveness of a combination of propofol and etomidate as pediatric anesthesia, and its influence on some vital factors in the patients.

Methods: A total of 104 children who underwent appendectomy, hepatobiliary surgery and excision of bone tumor in Xuzhou Children's Hospital, Xuzhou Medical University, Xuzhou, China from June 2018 to June 2020, were selected for this retrospective study. The patients were divided into groups $A, B$ and C. In group A, 40 patients received the combination of propofol and etomidate, 32 patients received propofol only, while group C comprised 32 patients who received etomidate only. Vital indices such as anesthesia induction time, wake-up time after surgery, anesthetic effect, and adverse reactions were determined.

Results: In group A, the mean arterial pressure (MAP) and heart rate (HR) were improved; anesthesia induction time and wake-up time after surgery were shorter, and anesthetic effect was more obvious in children with grades I and II. However, there was no grade III anesthetic effect, although there was a lower incidence of adverse reactions in this group.

Conclusion: The use of a combination of propofol and etomidate results in higher clinical efficacy of pediatric anesthesia than either propofol or etomidate alone. Furthermore, the combination produces better quality of vital indices in the patients.
\end{abstract}

Keywords: Propofol, Etomidate, Pediatric anesthesia, Mean arterial pressure, Heart rate, Anesthetic effect

\begin{abstract}
This is an Open Access article that uses a funding model which does not charge readers or their institutions for access and distributed under the terms of the Creative Commons Attribution License (http://creativecommons.org/licenses/by/4.0) and the Budapest Open Access Initiative (http://www.budapestopenaccessinitiative.org/read), which permit unrestricted use, distribution, and
\end{abstract} reproduction in any medium, provided the original work is properly credited.

Tropical Journal of Pharmaceutical Research is indexed by Science Citation Index (SciSearch), Scopus, International Pharmaceutical Abstract, Chemical Abstracts, Embase, Index Copernicus, EBSCO, African Index Medicus, JournalSeek, Journal Citation Reports/Science Edition, Directory of Open Access Journals (DOAJ), African Journal Online, Bioline International, Open-J-Gate and Pharmacy Abstracts

\section{INTRODUCTION}

Anesthesia is required in many treatments and operations for childhood diseases such as acute delirium, tonsillectomy and adenoidectomy, and trauma [1-3]. However, there are differences in anatomy, physiology, pharmacology, emotion and social intercourse between infants and adults. Therefore, the requirement for anesthesia differs between children and adults [4]. Although most anesthetic agents are safe for the clinical treatment of infants and young children, improper operation may result in serious critical events such as respiratory emergency, cardiac arrest and cardiovascular instability. Only centers with relevant equipment and physical environment 
can operate and anesthetize children after formal staff training [5-8]. It is essential to minimize safety problems caused by pediatric anesthesia $[9,10]$. At the same time, the selection of anesthetic drugs is a crucial factor for the safety of pediatric anesthesia.

Etomidate and propofol are good anesthetic drugs which are clinically used in many cardiovascular diseases, and also in gastroscopy $[11,12]$. Propofol is a $y$-aminobutyric acid (GABA) receptor agonist. Due to its fast efficacy and low incidence of postoperative nausea and vomiting, propofol has been widely used clinically for decades [13]. However, the use of propofol is also associated with some adverse effects. The most common adverse effects are pain from propofol injection, cardiovascular diseases (bradycardia and hypotension) and hyperlipidemia caused by lipid infusion [14]. Etomidate produces sedative and hypnotic effects, making it useful as an anesthetic agent in clinical practice $[15,16]$. However, the injection of this drug also causes pain, as well as adverse reactions such as thrombophlebitis and myoclonia $[17,18]$. Not much is known on the efficacy of the use of combination of the two drugs as pediatric anesthesia. Therefore, the purpose of the present study was to investigate the clinical efficacy of propofol-etomidate combination when used as pediatric anesthesia, and its effect on vital indexes in the patients.

\section{METHODS}

\section{Patients' profiles}

A total of 104 children who underwent appendectomy, hepatobiliary surgery and excision of bone tumor in Xuzhou Children's Hospital, Xuzhou Medical University, Xuzhou, China from June 2018 to June 2020, were selected for this retrospective study. They were divided into three groups $A, B$, and $C$. In group $A$, there were 40 children who received combination of propofol and etomidate; their mean age was $6.79 \pm 0.98$ years, and their mean body weight was $22.38 \pm 1.56 \mathrm{~kg}$. In group $B$, there were 32 children (mean age $=6.54 \pm 1.15$ years; mean body weight $=21.94 \pm 2.07 \mathrm{~kg}$ ) who received propofol only. There were 32 patients in group $\mathrm{C}$ (mean age was $=6.83 \pm 1.01$ years; mean body weight $=21.94 \pm 2.07 \mathrm{~kg}$ ), and they were given etomidate anesthesia only. The guardians of the children gave consent for them to participate in the study and signed informed consent forms. The study received approval from the institutional medical ethics committee, and followed international guidelines for human studies.

\section{Inclusion and exclusion criteria}

Inclusion criteria: Children in the following categories were enrolled in this study: children aged $\leq 12$ years, who were on admission and received surgical treatment in our hospital; children who did not suffer from serious complications and other diseases that might affect the test results; children whose guardians knew about the anesthesia programs and provided all data needed by the research institute, and children with American Society of Anesthesiologists (ASA) classification grades of I and II [19].

Exclusion criteria: Children who had diseases that might affect the results of this study; children who were allergic to the drugs or the equipment used in this study, those with anemia symptoms, and children with ASA grades above grade III, were excluded from the study.

\section{Treatments and assessment of outcomes}

All children were asked to stop fluid intake $2 \mathrm{~h}$ prior to the surgery, and they were fasted for $6 \mathrm{~h}$ before operation, without any premedication. The vein of each patient was opened and the vein passage of the upper limb was established. Then, the monitor was connected for determination of vital indexes such as blood pressure, breathing, heart rate $(\mathrm{HR})$ and blood oxygen saturation $\left(\mathrm{SpO}_{2}\right)$. Based on these data, anesthesia was induced. Children in group $A$ were treated with combination of propofol and etomidate. Fentanyl (Yichang Renfu Pharmaceutical Group Co. Ltd, batch number: $\mathrm{H}$ 4202076, specification: $0.1 \mathrm{mg}$ in $2 \mathrm{~mL}$ ) was injected intravenously at a dose of $1 \mu \mathrm{g} / \mathrm{kg}$. Then, propofol (Sichuan Guorui Pharmaceutical Co. Ltd., specification: $20 \mathrm{~mL}, 0.2 \mathrm{~g}$; batch no. 1603102) was slowly injected at a dose of 0.6 $\mathrm{mg} / \mathrm{kg}$, followed by etomidate $(0.2-0.4 \mathrm{mg} / \mathrm{kg})$. Children in group $\mathrm{B}$ were treated with propofol alone. Fentanyl $(0.1 \mathrm{mg}, 1 \mu \mathrm{g} / \mathrm{kg})$ was injected first, followed by propofol $(0.6 \mathrm{mg} / \mathrm{kg})$. Those in group $\mathrm{C}$ were treated with etomidate alone.

Just like in groups $A$ and $B$, fentanyl $(1 \mu \mathrm{g} / \mathrm{kg}$ ) was injected first, followed by etomidate (0.2-0.4 $\mathrm{mg} / \mathrm{kg}$ ). Vital indices such as $\mathrm{HR}$ and mean arterial pressure (MAP) were monitored and compared before, during and after the operation. Anesthesia induction time and post-surgery wake-up time were determined. Besides, anesthetic effects were compared and divided into three grades (I, II and III). If the patient was calm during the operation, and HR increased by less than $20 \%$, when compared with the basal value; blood pressure increased by less than 
$15 \%$ and the operation was not disrupted/impeded, this status was consistent with grade 1 . For grade II, the patient was mildly excited during the operation; HR increased by < $30 \%$, relative to basal level, blood pressure increased by less than $20 \%$, with slight body movements, and slight increase in respiratory frequency, but the surgery was not affected. Grade III anesthetic effect was for patients who were visibly agitated during the operation, with $\mathrm{HR}$ and blood pressure increased by more than 30 and $20 \%$, respectively. Moreover, respiratory frequency should be markedly increased, and there should be obvious body movements during the surgery, thereby necessitating additional dose of the anesthesia in order to continue with the operation.

The incidence of postoperative adverse reactions in the children were statistically analyzed and compared.

\section{Statistical analysis}

Data were statistically analyzed using SPSS 19.0 (Asia Analytics, formerly SPSS China). Counting data such as anesthesia effect, postoperative adverse reactions, and some general data were analyzed using $x^{2}$ test. Measurement data such as anesthesia induction time, wake-up time postsurgery, systolic pressure, diastolic pressure, and MAP are expressed as mean \pm standard deviation (SD), and were analyzed using $t$-test. Values of $p<0.05$ were taken as indicative of statistically significant differences.

\section{RESULTS}

\section{General information on patients}

There are no significant differences amongst the three groups in terms of patient profiles such as gender, gestational age, body weight, and CT results $(p>0.05)$.

\section{Vital signs of patients}

The MAP values of patients in group A before, during and after operation were 81.54 \pm 6.65 , $87.32 \pm 7.09$ and $82.12 \pm 5.43 \mathrm{mmHg}$, respectively. In group $B$, the MAP values before, during and after surgery were $81.88 \pm 6.43,93.23 \pm 11.23$, and 85.45 $\pm 7.37 \mathrm{mmHg}$, respectively. The corresponding MAP values in group $\mathrm{C}$ were $82.35 \pm 6.43, \quad 103.24 \pm 14.57$ and $95.65 \pm 8.65$ $\mathrm{mmHg}$, respectively. Thus, MAP recovery was markedly better in group $A$ than in groups $B$ and C.

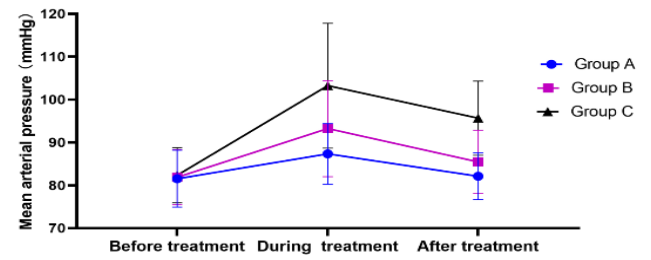

Figure 1: MAP levels of children in the three groups before, during and after operation. The MAP recovery was markedly better in group A than in B and $C(p<$ 0.05)

Table 1: General information on patients

\begin{tabular}{|c|c|c|c|c|c|}
\hline Group & Group A $(n=40)$ & Group B $(n=32)$ & Group C ( $n=32)$ & $F / X^{2}$ & $P$-value \\
\hline Gender & & & & 0.57 & 0.751 \\
\hline Male & $21(50.25)$ & $18(56.25)$ & $15(46.87)$ & & \\
\hline Female & $19(49.75)$ & $14(43.75)$ & $17(53.13)$ & & \\
\hline Age (years) & $6.79 \pm 0.98$ & $6.54 \pm 1.15$ & $6.83 \pm 1.01$ & 0.74 & 0.479 \\
\hline $\begin{array}{l}\text { Average body } \\
\text { weight }(\mathrm{kg})\end{array}$ & $22.38 \pm 1.56$ & $21.94 \pm 2.07$ & $22.45 \pm 2.13$ & 0.69 & 0.50 \\
\hline $\begin{array}{l}\text { ASA } \\
\text { classification }\end{array}$ & & & & 0.57 & 0.753 \\
\hline Grade I & $22(55.00)$ & $16(50.00)$ & $19(59.38)$ & & \\
\hline Grade II & $18(45.00)$ & $16(50.00)$ & $13(40.62)$ & & \\
\hline $\begin{array}{l}\text { Classification of } \\
\text { diseases }\end{array}$ & & & & 5.73 & 0.678 \\
\hline Appendectomy & $8(20.00)$ & $6(52.00)$ & 7 & & \\
\hline $\begin{array}{l}\text { Hepatobiliary } \\
\text { surgery }\end{array}$ & $5(12.50)$ & $7(22.00)$ & 4 & & \\
\hline $\begin{array}{l}\text { Excision of bone } \\
\text { tumor }\end{array}$ & $9(15.00)$ & $5(22.00)$ & 6 & & \\
\hline $\begin{array}{l}\text { Intestinal } \\
\text { obstruction } \\
\text { operation }\end{array}$ & 11 & 12 & 13 & & \\
\hline Hernia surgery & $7(10.00)$ & $2(2.50)$ & 2 & & \\
\hline
\end{tabular}




\section{Heart rate (HR)}

The HR of patients in group A before, during and after operation were 102.11 \pm 10.43 ,

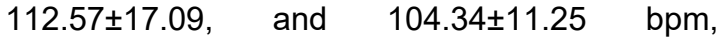
respectively. The HR of those in group $B$ before, during and after operation were 101.94 \pm 10.54 , $124.46 \pm 18.23$, and $112.67 \pm 11.65 \mathrm{bpm}$, respectively, while the $\mathrm{HR}$ of the corresponding values for group $\mathrm{C}$ before, during and after operation were 102.35 $\pm 11.02,134.21 \pm 17.33$, and $125.78 \pm 12.16 \mathrm{bpm}$, respectively. Thus, there was markedly better HR recovery in group $A$, relative to $B$ and $C$.

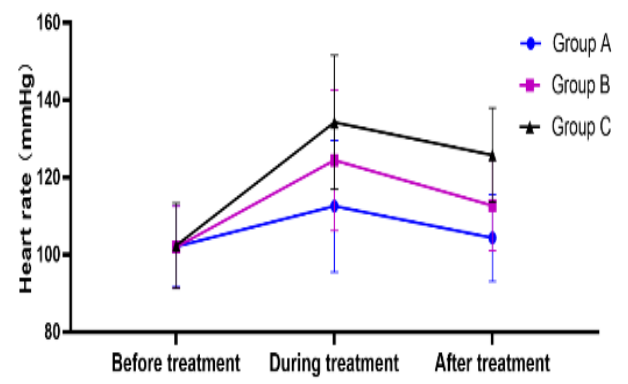

Figure 2: HR values of children in the three groups before, during and after operation. The HR recovery was significantly better in group $A$ than in groups $B$ and $\mathrm{C}(p<0.05)$

\section{Anesthesia induction time}

The anesthesia induction times of patients in groups A, B and C were 112.27 \pm 12.45 , 127.23 \pm 16.34 , and 135.31 $\pm 21.13 \mathrm{sec}$, respectively. Anesthesia induction times of patients in groups $A$ and $B$ were significantly lower than that of those in group $\mathrm{C}$, while anesthesia induction time was significantly lower in group $A$ than in group $B(p<0.05)$.

\section{Wake-up time after surgery}

The wake-up time of patients in groups A, B and $C$ were $22.56 \pm 4.45,32.23 \pm 4.34$ and $41.76 \pm 6.13$ min, respectively. The wake-up times of patients in groups $A$ and $B$ were significantly shorter than that of patients in group $C$, while wake up time was markedly shorter in group $A$ than in group $B$ $(p<0.05)$.

\section{Anesthetic effect}

In group A, there were 24 patients in anesthetic grade I, 16 patients in anesthetic grade II, and no patients in anesthetic grade III. In group B, there were 12 patients in anesthetic grade I, 14 patients in anesthetic grade II, and 6 patients in anesthetic grade III. In group C, there were 10 patients in anesthetic grade I, 14 patients in anesthetic grade II, and 8 patients in anesthetic grade III. The anesthesia effect in patients in group A was markedly lower $(p<0.05)$ than those of patients in groups $\mathrm{B}$ and $\mathrm{C}$.



Figure 3: Comparison of anesthesia induction time amongst the 3 groups of patients. The anesthesia induction times of patients in groups $A$ and $B$ were significantly lower than that of those in group $C$, while anesthesia induction time was significantly lower in group A than in group $B .{ }^{* \wedge} P<0.05$, vs group $C$; ${ }^{*} p<$ $0.05)$, vs group $B$

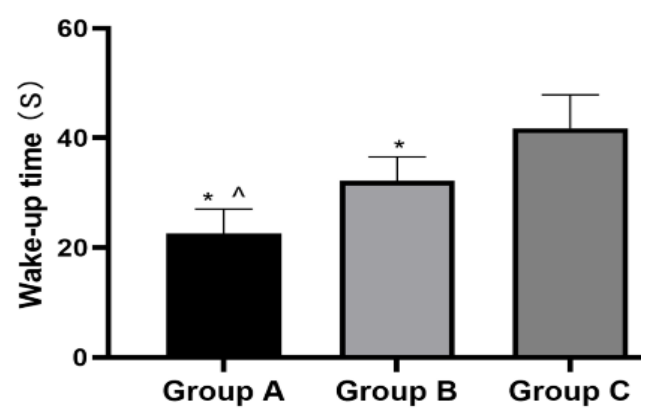

Figure 4: Comparison of wake-up time after operation amongst children in the three groups. The wake-up times of patients in groups A and B were significantly shorter than that of patients in group $C$, while wake-up time was markedly shorter in group $A$ than in group $B$. ${ }^{\star \wedge} P<0.05$, vs group $C ;{ }^{*} p<0.05$ ), vs group $B$

Table 2: Anesthetic effect in children

\begin{tabular}{lccccc}
\hline Variable & Group A (n=40) & Group B (n=32) & Group C (n=32) & t & P-value \\
\hline Grade I & $24(60.00)$ & $12(37.50)$ & $10(31.25)$ & 6.81 & 0.033 \\
Grade II & $16(40.00)$ & $14(43.75)$ & $14(43.75)$ & 0.14 & 0.932 \\
Grade III & $0(0.00)$ & $6(18.75)$ & $8(25.00)$ & 10.65 & 0.005 \\
\hline
\end{tabular}

Data are presented as frequency and percentage [n (\%)] 
Table 3: Incidence of adverse reactions in the three groups of patients

\begin{tabular}{|c|c|c|c|c|c|}
\hline Variable & $\begin{array}{c}\text { Group A } \\
(n=40)\end{array}$ & $\begin{array}{c}\text { Group B } \\
(n=32)\end{array}$ & $\begin{array}{c}\text { Group C } \\
(n=32)\end{array}$ & $\mathbf{t}$ & $P$-value \\
\hline $\begin{array}{l}\text { Respiratory } \\
\text { depression }\end{array}$ & $0(0.00)$ & $2(6.25)$ & $12(37.50)$ & 23.52 & $<0.001$ \\
\hline Dysphoria & $2(5.00)$ & $8(25.00)$ & $14(43.75)$ & 16.16 & $<0.001$ \\
\hline $\begin{array}{l}\text { laryngospasm and } \\
\text { bronchospasm }\end{array}$ & $0(0.00)$ & $2(6.25)$ & $10(31.25)$ & 18.28 & $<0.001$ \\
\hline $\begin{array}{l}\text { Nausea and } \\
\text { vomiting }\end{array}$ & $1(2.50)$ & $6(18.75)$ & $12(37.50)$ & 14.59 & $<0.001$ \\
\hline
\end{tabular}

Data are presented as frequency and percentage [n (\%)]

\section{Adverse reactions}

In group $A$, there were 2 cases of dysphoria, 1 case of nausea and vomiting, and no cases of respiratory depression, laryngospasm and bronchospasm. In group B, there were 2 cases of respiratory depression, 8 cases of dysphoria, 2 cases of laryngospasm and bronchospasm, and 6 cases of nausea and vomiting. In group $\mathrm{C}$, there were 12 cases of respiratory depression, 14 cases of dysphoria, 10 cases of laryngospasm and bronchospasm, and 12 cases of nausea and vomiting. The incidence of adverse reactions in group $A$ patients was significantly lower than those in groups B and C $(p<0.05)$.

\section{DISCUSSION}

Propofol, etomidate and their combination are relatively frequently used in clinics [20-22]. However, there are limited clinical studies on anesthesia for surgery in children. In this study, the clinical efficacy of combination of the two drugs was investigated. Data on vital indexes of patients in the three groups were first analyzed. It was found that the recovery of vital signs in group $A$ which received combination of propofol and etomidate was markedly better than those in group B which received propofol alone, and group $\mathrm{C}$ given etomidate alone. This meant that the recovery of vital signs was significantly better in the propofol-etomidate combination group than in propofol or etomidate when used alone. Propofol slows down the channel closing time and activates related receptors. However, it causes local pain and discomfort at the injection site, which sometimes brings suffering to patients [23]. Thus, there is need to combine propofol with other drugs. Etomidate is faster in action than propofol. It is widely used an anesthesia for patients with cardiovascular disease (e.g., coronary artery disease), and for those with poor cardiac reserve, indicating that it has little influence on hemodynamics and cardiovascular diseases. Indeed, etomidate exerts protective effect against cardiovascular and cerebrovascular diseases, and also mitigates problems caused by propofol [24-26]. In addition, since etomidate counteracts some side effects of propofol, the recovery of vital signs will be better for children under combination anesthesia with propofol and etomidate. Moreover, comparison of anesthesia induction time and wake-up time revealed that the anesthesia induction time and wake-up time of patients in group A were shorter than those of patients in group $B$ who received propofol alone, and patients in group $\mathrm{C}$ who were anesthetized with etomidate alone. Based on these results, it can be concluded that the anesthesia induction time and wake-up time of patients who received combination anesthesia were shorter than those of patients for whom only one drug was used.

Analysis of anesthetic effect in patients in group A who received combination of propofol and etomidate showed more patients in grades I and II, but no patient in grade III, when compared to groups $\mathrm{B}$ and $\mathrm{C}$ given propofol alone and etomidate alone, respectively, which had fewer patients in grades I and II. Studies have shown that propofol and etomidate produce good anesthetic effects $[27,28]$. In clinical studies on gastroscopy anesthesia for elderly patients, it was demonstrated that the combination of propofol and etomidate was safer and had better anesthetic effect, relative to the use of individual anesthetic. Moreover, the joint use of the two drugs improved hemodynamic stability, reduced side effects, and provided rapid recovery to fullyactive state [29].

In another comparative study on the influence of anesthesia on hemodynamic responses to tracheal intubation, it was found that combination of etomidate and propofol produced better effect than the use of etomidate or propofol alone, and it maintained better hemodynamic stability than the single drugs when used alone [30]. The results obtained in this study are consistent with these findings. To sum up, the joint use of etomidate and propofol resulted in better effect on the hemodynamic stability of patients, reduced complications, decreased anesthesia 
induction time and wake-up time, and superior anesthesia effect.

\section{Limitations of the study}

Since this investigation was a retrospective study, the use of equipment was limited. Thus, there were no measurements of levels of some molecular indicators, or identification of the specific molecular pathways affected by the two drugs. These would have been useful in elucidating the specific molecular mechanisms involved in the anesthetic effects of these drugs. These limitations should form the major focus of future investigations.

\section{CONCLUSION}

Overall, this study has demonstrated that for pediatric anesthesia, the combination of propofol and etomidate has a greater clinical efficacy than either propofol or etomidate, Moreover, the combination produces greater improvement in vital indices of the patients.

\section{DECLARATIONS}

\section{Conflict of interest}

No conflict of interest is associated with this work.

\section{Contribution of authors}

We declare that this work was done by the author(s) named in this manuscript, and all liabilities pertaining to claims relating to the content of this article will be borne by the authors. $\mathrm{LL}$ and $\mathrm{FZ}$ conceived and designed the study, and drafted the manuscript. LL, YD, JY and QS collected, analyzed and interpreted the experimental data. $\mathrm{FZ}$ revised the manuscript for important intellectual content. All authors read and approved the final manuscript.

\section{Open Access}

This is an Open Access article that uses a funding model which does not charge readers or their institutions for access and distributed under the terms of the Creative Commons Attribution License (http://creativecommons.org/licenses/by/ 4.0) and the Budapest Open Access Initiative (http://www.budapestopenaccessinitiative.org/rea d), which permit unrestricted use, distribution, and reproduction in any medium, provided the original work is properly credited.

\section{REFERENCES}

1. Moore $A D$, Anghelescu $D L$. Emergence delirium in pediatric anesthesia. Pediatric Drugs 2017; 19: 11-20.

2. Hoagland $M$, Mandler $T$, Schwartz LI. Pediatric Anesthesia. 2018.

3. Sofer M. Does Rapid Sequence Induction Have a Role in Pediatric Anesthesia? Springer, Cham; 2017. pp111113.

4. Tesoro S, Marchesini L, De Robertis E. Pediatric Anesthesia. Translational Medicine@ UniSa 2019; 20: 1.

5. Habre W, Disma N, Virag K, Becke K, Hansen TG, Johr $M$, Leva B, Morton NS, Vermeulen PM, Zielinska $M$, et al. Clinical Trial Network. Incidence of severe critical events in paediatric anaesthesia (APRICOT): a prospective multicenter observational study in 261 hospitals in Europe. Lancet Respir Med 2017; 5: 412425.

6. Sims C, Farrell T. An Overview of Pediatric Anesthesia. Springer, Cham; 2020. pp 1-26.

7. Zgleszewski SE, Graham DA, Hickey PR, Brustowicz $R M$, Odegard KC, Koka R, Seefelder C, Navedo AT, Randolph AG. Anesthesiologist-and system-related risk factors for risk-adjusted pediatric anesthesia-related cardiac arrest. Anesth Analg 2016; 122: 482-489.

8. Isokääntä S, Koivula K, Honkalampi K, Kokki $H$. Resilience in children and their parents enduring pediatric medical traumatic stress. Pediatr Anesth 2019; 29: $218-225$.

9. Spaeth JP, Kreeger $R$, Varughese AM, Wittkugel E. Interventions designed using quality improvement methods reduce the incidence of serious airway events and airway cardiac arrests during pediatric anesthesia. Pediatr Anesth 2016; 26: 164-172.

10. O'Leary JD, Janus $M$, Duku E, Wijeysundera $D N$, To $T, L i$ $P$, Maynes JT, Faraoni D, Crawford MW. Influence of surgical procedures and general anesthesia on child development before primary school entry among matched sibling pairs. JAMA Pediatr 2019; 173: 29-36.

11. Baradari AG, Firouzian A, Kiasari AZ, Aarabi M, Emadi SA, Davanlou A, Motamed N, Yousefi Abdolmaleki E. Effect of etomidate versus combination of propofolketamine and thiopental-ketamine on hemodynamic response to laryngoscopy and intubation: a randomized double blind clinical trial. Anesth Pain Med 2016; 6: e30071.

12. Chen L, Liang X, Tan X, Wen H, Jiang J, Li Y. Safety and efficacy of combined use of propofol and etomidate for sedation during gastroscopy: Systematic review and meta-analysis. Medicine (Baltimore) 2019; 98: e15712.

13. Sahinovic MM, Struys MMRF, Absalom AR. Clinical pharmacokinetics and pharmacodynamics of propofol. Clinical pharmacokinetics 2018; 57: 1539-1558.

14. Marik PE. Propofol: therapeutic indications and sideeffects. Curr Pharm Des 2004; 10: 3639-3649.

15. McGrath M, Ma C, Raines DE. Dimethoxy-etomidate: a nonhypnotic etomidate analog that potently inhibits

Trop J Pharm Res, September 2021; 20(9): 1980 
steroidogenesis. J Pharmacol Exp Ther 2018; 364: 229237.

16. Aggarwal S, Goyal VK, Chaturvedi SK, Mathur V, Baj B, Kumar A. A comparative study between propofol and etomidate in patients under general anesthesia. Braz J Anesthesiol 2016; 66: 237-241.

17. Nyman Y, Von Hofsten K, Palm C, Eksborg S, Lönnqvist $P A$. Etomidate-Lipuro is associated with considerably less injection pain in children compared with propofol with added lidocaine. Br J Anaesth 2006; 97: 536-539.

18. Nyman $Y$, von Hofsten K, Ritzmo C, Eksborg S, Lönnqvist $P$ A. Effect of a small priming dose on myoclonic movements after intravenous anaesthesia induction with Etomidate-Lipuro in children. $\mathrm{Br} \mathrm{J}$ Anaesth 2011; 107: 225-228.

19. Doyle DJ, Garmon EH. American Society of Anesthesiologists classification (ASA class) StatPearls [Internet]. StatPearls Publishing, 2019.

20. Karthik $P$, Alarasan AK, Balamurugan B. Haemodynamic effects of etomidate, propofol and their combination on induction and intubation: A prospective randomized clinical trial. Indian J Clin Anaesth 2019; 6: 180-186.

21. Adinehmehr L, Shetabi $H$, Farsani $D$, Salehi $A$, Noorbakhsh M. Comparison of the sedation quality of etomidate, propofol, and midazolam in combination with fentanyl during phacoemulsification cataract surgery: a double-blind, randomized, controlled, clinical trial. Anesth Pain Med 2019; 9: e87415.

22. Maldifassi M C, Baur R, Sigel E. Functional sites involved in modulation of the GABAA receptor channel by the intravenous anesthetics propofol, etomidate and pentobarbital. Neuropharmacol 2016; 105: 207-214.

23. Prerna B, Shalendra S, Priya T. Application of 'Priming Principle' on the induction dose requirements of propofol
- A Randomized Clinical Trial. Int J Biomed Res 2018; 9: 320-324.

24. Song JC, Lu ZJ, Jiao YF, Yang B, Gao H, Zhang J, Yu WF. Etomidate anesthesia during ERCP caused more stable haemodynamic responses compared with propofol: a randomized clinical trial. Int J Med Sci 2015; 12: 559-565.

25. Shah SB, Chowdhury I, Bhargava AK, Sabbharwal B. Comparison of hemodynamic effects of intravenous etomidate versus propofol during induction and intubation using entropy guided hypnosis levels. J Anaesthesiol Clin Pharmacol 2015; 31: 180-185.

26. Rathore VS, Singh S, Taank $P$, Khandelwal A, Kaushal A. Clinical Analysis of Propofol, Etomidate and an Admixture of Etomidate and Propofol for Induction of General Anaesthesia. Turk J Anaesthesiol Reanim 2019; 47: 382-386.

27. Zhang L, Bao Y, Shi D. Comparing the pain of propofol via different combinations of fentanyl, sufentanil or remifentanil in gastrointestinal endoscopy. Acta cirurgica brasileira 2014; 29: 675-680.

28. Liu J, Liu R, Meng C, Cai Z, Dai X, Deng C, Zhang J, Zhou H. Propofol decreases etomidate-related myoclonus in gastroscopy. Medicine (Baltimore) 2017; 96: e7212.

29. Meng QT, Cao C, Liu HM, Xia ZY, Li W, Tang LH, Chen $R$, Jiang $M, W u Y$, Leng $Y$, et al. Safety and efficacy of etomidate and propofol anesthesia in elderly patients undergoing gastroscopy: A double-blind randomized clinical study. Exp Ther Med 2016; 12: 1515-1524.

30. Babu BVM, Chandra BAS. A Comparative Study of Effect of Etomidate, Propofol and Etomidate Plus Propofol Induction on Hemodynamic Response to Endotracheal Intubation: A Prospective Randomized Controlled Study 2019. 